\title{
IDENTIDAD FEMENINA, MEMORIA Y (RE)CREACIÓN DE SÍ, EN LA VIRGEN DE LAS ANTENAS DE BEGONIA UGALDE
}

\author{
Alicia Salomone \\ Universidad de Chile \\ aliciasalomone@yahoo.com
}

Palabras clave: poesía chilena de mujeres, La virgen de las Antenas, Begonia Ugalde.

KEY WORDS: Chilean female poetry, La virgen de las Antenas, Begonia Ugalde.

Cada jornada idéntica a la anterior

un poco despierta e ida

menos los tímpanos

porque alerta siempre al llamado

urgente la vigilia asoma

madriguera.

Resbalan las horas a destiempo

el niño, pequeña bestia,

chupa para agrandarse,

la madre, de calcio

no sabe

cómo dejar de ser madre

(de "Misterios dolorosos", La virgen de las antenas)

No es la primera vez que, en la poesía chilena de mujeres, se establecen relaciones productivas entre una hablante lírica y la Virgen del cerro San Cristóbal, renombrada aquí con el apelativo más contemporáneo de la Virgen de las Antenas. Por citar solo una referencia próxima, vale la pena recordar que Eugenia Brito convocó a la misma 
figura, en los años ochenta, en sus poemarios Vía pública (1984) y Filiaciones (1986), presentándola como la acompañante de una mujer fantasma en su recorrido por una ciudad devastada ${ }^{1}$. Fuera de Chile, Rosario Ferré ya había instalado a la Virgen, también con sentido crítico, en su nouvelle La Bella Durmiente (1976); un relato donde María es más una diosa arcaica que una virgen cristiana, emergiendo como el único referente válido para la protagonista, una joven de la élite portorriqueña cuya pasión por la danza chocaba con los ideales que prevalecían en su medio social y familiar.

Estas recurrencias, sin embargo, no pueden extrañar en la literatura actual de mujeres, pues, según explica Julia Kristeva en su ensayo de 1983: "Stabat Mater” (1987), la imagen de la Virgen María, con sus más de dos mil años de historia, es una de las construcciones simbólicas que ha tenido mayor influencia en la constitución de la identidad femenina occidental, en especial, debido a su asociación con la maternidad.

Ahora bien, como sostiene Kristeva, si de una mujer es incierto predicar que sea, es decir, que se defina como sujeto autónomo, a riesgo de abolir su diferencia, quizás no ocurra lo mismo con la madre, “dado que ésta es la única función del 'otro sexo' a la que podemos atribuir, con absoluta seguridad, una existencia" (Kristeva 209). Por cierto, esta relación ha traído no pocos problemas a las mujeres, y en particular al feminismo, a la hora de explorar en nuevas representaciones para la feminidad. Lo que ha derivado, en algunos casos, en negaciones y rechazos tajantes frente a la maternidad y, en otros, en idealizaciones acríticas en base a una supuesta esencia femenina matrística, sin que ello impida que la gran mayoría de las personas del mundo sigua aceptando de forma consciente o inconsciente las representaciones de género tradicionales.

Para Kristeva, estas visiones polarizadas sobre la maternidad, que suelen aparecer en ciertos feminismos, parten de un equívoco que debe ser despejado, pues no solo genera malos entendidos, sino que impide pensar de mejor manera sobre estos asuntos. Por un lado, sostiene la autora, hay que comprender que la representación consagrada de la maternidad, sea ésta laica o religiosa, es un imaginario y, por ende, no constituye un referente real. Por el contrario, dice Kristeva, deriva de la proyección de una fantasía alimentada en la adultez acerca de ese continente perdido que es el seno materno; un lugar donde se aloja el anhelo humano por acceder, alguna vez, a una relación nutricia con una madre que sea capaz de cubrir todas nuestras necesidades.

Esa figura totalitaria, que tiende a concentrar nuestras mayores expectativas y, al mismo tiempo, despierta las más intensas rebeldías suele soslayar, sin embargo, una importante experiencia real: la de una maternidad históricamente determinada. Una maternidad que, a diferencia de aquella visión ilusoria anclada en dolorosos sentimientos narcisistas, se conforma a partir de vivencias concretas que experimentan las mujeres, como la gestación, el parto, la crianza primera y, sobre todo, el ejercicio cotidiano de creación del vínculo emocional entre madre e hijo/a. Todas las cuales no solo tienen gran importancia en la vida individual de cada mujer, sino que determinan el papel que ellas

$\mathrm{Al}$ respecto, ver el muy buen estudio de Magda Sepúlveda sobre las poetas y su relación con la ciudad de Santiago en la postdictadura. 
detentan, en tanto colectivo, en su condición de productoras y reproductoras de vínculos afectivo-sexuales a nivel social.

El libro La Virgen de las Antenas, de Begonia Ugalde, instalando desde distintas perspectivas la problemática de la identidad-mujer, discurre de manera tensionada por estas dos líneas que acabo de señalar, la simbólica y la experiencial. Por un lado, en este texto se hace presente la feminidad modélica de índole mariana, ligada tanto a la imagen de la mater dolorosa como a los discursos que históricamente se han construido en torno de ella. Asimismo, esta representación también opera en el nivel de la plasmación formal del texto, en la medida en que este largo poema, compuesto de múltiples fragmentos organizados en doce secciones, establece su arquitectura discursiva desde una relación intertextual con el Santo Rosario católico. Ahora bien, junto con estas perspectivas que ligan el texto con la tradición canónica, se descubre una discursividad que, mediante el recurso a la parodia y la ironía frente a esos referentes, tanto en el plano de la forma como del contenido, da cauce al despliegue de una subjetividad femenina otra que se distancia del modelo instituido.

Así, el libro nos presenta a una figura femenina que también es una mater pero que, a diferencia de la modélica, ya no queda fijada en esa única posición ni misión, ni en el padecer que ambas conllevan, sino que oscila entre el dolor y el gozo, entre la luminosidad y la degradación, entre el afuera y el adentro, entre la hiperactividad y la introspección autorreflexiva. Como si la hablante, en sus evoluciones, terminara por asumir como propio un lugar de tensión productiva, donde se oponen dinámicamente la aceptación y la crítica respecto del rol femenino preponderante; lo que, al mismo tiempo, la habilita para explorar en nuevas formas del ser mujer, jugando con los distintos ropajes que están disponibles para (re)presentar la identidad femenina ${ }^{2}$.

En el marco de estas búsquedas, un elemento que me parece central es el modo en que se inscribe en el texto una poética del cuerpo, donde nuevamente destaca la diferencia respecto del modelo femenino mariano. Pues, si en éste la (ab)negación es clave, lo que se simboliza no solo en la entrega personal de María a los designios de la Providencia sino en el ocultamiento de su cuerpo, entendido como mero receptáculo o instrumento del mandato divino. En cambio, en la mujer que se va delineando en el libro de Begonia Ugalde la corporalidad adquiere un papel determinante, al punto que resulta la base material fundamental a partir de la cual la sujeto configura su experiencia. Desde esta otra posición, la de una sujeto-con-cuerpo, una sujeto incardinada en los términos de Patrizia Violi ${ }^{3}$, ella va recuperando los distintos registros de la experiencia que la han constituido como tal y, a partir de los recuerdos de esos distintos momentos y vivencias, puede reconstruir memoriosamente, es decir, críticamente, su trayecto vital.

2 Aludo aquí a las ideas propuestas de Judith Butler respecto de la identidad como representación; es decir, no como definición fija o esencial sino como un resultado preformativo.

3 Debatiendo con las corrientes lingüísticas trascendentalistas, Patrizia Violi sostiene la necesidad del anclaje del sujeto enunciador en el individuo, en tanto materialidad concreta que incorpora asimismo la experiencia de la diferencia sexual. 
Los perros de la casa materna

olfatean el desprendimiento.

Con aullidos prolongados

anuncian la nueva madre

se frotan en su panza abultada

advierten en gruñidos;

las paredes del canal deben ceder.

(...)

Tras cada contracción

nada cabe en el espacio abierto

sólo grito ahogado

(...)

Con la fuerza extraña de todo estallido primero

puja, la madre, desde los hombros

lo enraizado en cuarenta semanas de preguntas (9).

La hablante procede en el texto auscultando de cerca, y a través de todos sus sentidos, el cúmulo de percepciones y emociones que la rondan y que por momentos llegan a alcanzar una intensidad animal. Emociones y vivencias que se trasmutarán en una voz, sólidamente anclada en esa misma corporalidad, a través de la cual se procesarán no solo las sensaciones más primarias sino también los deseos y las creaciones, las luchas y fracasos, los dolores que surgen del abandono, el registro de la ciudad, y hasta el armado desarmado de vínculos con otros y con otras. Toda una trama discursiva y vivencial en cuyo tejido irá redefiniendo la propia subjetividad y abriendo espacio a esa "nueva madre" que se construye a sí misma de manera compleja, y no meramente reactiva ante los modelos recibidos. Como si quisiera dejarnos en claro que, al menos desde su experiencia, los tiempos de las identidades fijas o las opciones excluyentes han llegado a su fin, pues se puede ser mujer (y aun madre) de uno u otro modo, sin que ello implique contradicciones imposibles de salvar.

En ocasiones, esa voz que se constituye a lo largo del poema se articula desde un yo personal, sobre todo cuando apela a una discursividad modelada bajo un registro autobiográfico, como en la sección "Semanas santas (diario de infancia)", donde la hablante vuelve a ciertas escenas de la niñez, recordando con ironía sus ejercicios de resistencia frente a la disciplina impuesta desde el aula y los ritos religiosos:

No aprendo los mandamientos, me saco malas notas en religión, no me gusta estudiar las parábolas ni logro colorear dibujos sin salirme del contorno, las canciones de panes y corderos callo en la liturgia sus letras de memoria. No aprendo a tejer mantas para mis futuros hijos, a callar el reclamo dejar quietos mis dedos, a llevar el delantal limpio 
a distinguir el camino al cielo

porque es muy tenue la luz que lo señala

("Primera confesión" 26)

En otros momentos, sin embargo, aquella voz se exterioriza, asumiendo la forma de un relato, construido en tercera persona, acerca de una vida otra, como ocurre en las dos primeras secciones del texto ("Misterios gloriosos" y "Misterios dolorosos"), las que están centradas en las vivencias del embarazo, el parto y la primera crianza. Así, a diferencia de aquella escritura donde prima el registro testimonial, en esta otra modalidad, lo que domina es el pliegue autorrefexivo, que parece señalarnos un alejamiento o toma de distancia de la hablante frente a lo vivido. Un gesto que quiere hacer visible a los lectores y lectoras esa cesura que inevitablemente media entre la sujeto que enuncia y aquélla que es narrada en el texto: entre ésa que vive y esa otra que la mira (o que se mira) vivir. En otras partes del poema, no obstante, esas dos modalidades de enunciación se entremezclan y confunden, dando paso la una a la otra, en un ejercicio multivocal y multifocal que no es ajeno a las formas en que históricamente se han expresado las mujeres, según sabemos por las indagaciones de la ginocrítica, y que nos permite observar, desde distintos ángulos, los múltiples fragmentos y perfiles que conforman esa identidad otra que está siendo plasmada en el texto ${ }^{4}$.

Como mencioné más arriba, la estructura de este libro se encuentra estrechamente vinculada con la discursividad mariana, pues de hecho adopta la forma de una reescritura paródica, y por ende crítica, del Santo Rosario ${ }^{5}$. Al respecto, vale la pena recordar que el Rosario es un rezo de la Iglesia que tiene por objeto promover en los fieles la

$4 \quad$ Entiendo la ginocrítica a partir de las propuestas de Elaine Showalter quien, retomando las hipótesis bajtinianas sobre el dialogismo, propone la bivocalidad como una característica bivocalidad que se observa en la escritura de mujeres, y que remite a la presencia de, al menos, dos discursos en esta textualidad. Por un lado, un discurso oficial, socialmente más aceptable, y por otro, un discurso silenciado o borroso, por lo común menos legitimado, que suele plantear un contrapunto frente al primero.

Defino la parodia desde las formulaciones de Linda Hutcheon (177-178), como un fenómeno discursivo o literario de índole intertextual, en el que se superponen dos textos. A nivel de su estructura formal, un texto paródico supone la incorporación de un texto parodiado (de segundo plano) en un texto parodiante, produciendo un engarce de lo viejo en lo nuevo. Hay que agregar, por otra parte, que esa síntesis bitextual funciona siempre de forma paradójica, evidenciando una transgresión a la norma o doxa litearia, lo que distingue a la parodia de otras modalidades intertextuales que buscan resaltar la semejanza entre los textos superpuestos. En cuanto a la ironía, también a partir de Hutcheon, la asumo desde la confluencia entre funciones semánticas y pragmáticas que convocan, al mismo tiempo, el disimulo y la interrogante; es decir, un desfase entre significaciones que también supone un juicio crítico. La ironía, por tanto, es, al mismo tiempo, una estructura antifrástica y una estrategia evaluativa; la que si, por un lado, conlleva una intencionalidad del autor-codificador con respecto al texto, por otro, permite y exige, al lector-descodificador, interpretar y evaluar el texto que está leyendo (Hutcheon 176-177). 
contemplación y la meditación acerca de los veinte misterios principales de la vida de Cristo y de la Virgen María ${ }^{6}$. Desde la perspectiva católica, estos misterios se integran en cuatro grupos: los gozosos, los luminosos, los dolorosos y los gloriosos, los que, en ese orden, marcan el tránsito que va desde la Anunciación y la Encarnación, pasando por la Pasión de Cristo en la Cruz, hasta la venida del Espíritu y la ascensión de la Virgen a los cielos. Hay que señalar, por otra parte, que, si bien el Rosario posee un carácter mariano, es una oración centrada en la cristología, en la medida en que sintetiza el conjunto del mensaje evangélico. De lo que se deduce, finalmente, que el papel que allí le cabe, tanto a María como al eco de su Magnificat ante la obra de la Encarnación, no es el de un agente activo sino el de una figura mediadora a través de la cual el pueblo cristiano aprende a contemplar la belleza de Cristo y a experimentar la hondura de su amor y su misión.

El texto de Begonia Ugalde, que parte de este hipotexto, sin embargo, modifica sustancialmente su orden y sentido, mediante una serie de operaciones textuales que distorsionan irónicamente esa estructura primera. Entre las múltiples estrategias que este texto entrega, una de las más interesantes es el gesto de redefinir los misterios y de alterar el lugar que tienen en la inscripción dogmática, lo que supone otorgarles coherencias y significados alternativos, que cuestionan la orientación providencialista del modelo canónico. Así, por ejemplo, en la primera sección del texto, los "Misterios gloriosos", que ocupa el puesto de los "Misterios gozosos" en el Rosario cristiano, la trascendencia no aparece ligada a la historia de una salvación que hay que alcanzar en el Reino de los Cielos, sino que se proyecta en una historia más pequeña y mundana, pero no menos luminosa ni sagrada (gloriosa, desde la perspectiva de la hablante), como es el proceso que da lugar a la creación, desde el propio cuerpo, representada en el nacimiento de un nuevo ser, que es a la vez el hijo y el poema mismo.

Por su parte, los "Misterios gozosos" del texto, lejos de estar centrados en la alegría mariana por la Encarnación, nos hablan del descubrimiento de otro tipo de placeres, en ese momento de pasaje entre la niñez y la adolescencia, donde las búsquedas, juegos y apropiaciones del cuerpo y el deseo resultan el soporte necesario desde el cual redefinir una identidad infantil que ya se está dejando atrás. Un cuerpo que debe hacerse fuerte, también, como el contrapeso indispensable para operar el doloroso trabajo de autonomización de la hablante frente a la figura materna, que siempre es para ella un referente amoroso e inmediato, pero del que inevitablemente deberá escindirse.

Esa noche que escapé por la ventana

no estuve sola, mamá, te juro

permanecimos unidas

como hermanas de sangre,

tomadas de la mano avanzamos entre ellos

comprendiendo que deseaban tocarnos

6 El Rosario con los misterios comentados e ilustrados. Al respecto, ver la publicación realizada por la orden franciscana en: http://www.franciscanos.org/oracion/rosario.html. 
por tener las caderas sin marcas,

los ojos febriles

y tantas ganas de llevarnos las guirnaldas

para colgarlas sobre el respaldo de la cama,

prolongando así

nuestra única fiesta (35).

Solo quisiera señalar, para concluir estas notas, que el proceso subjetivo que la hablante va reconstruyendo a lo largo de texto es, sin duda, complejo, y supone un esfuerzo que, por momentos, parece dejarla exhausta, como nos sugiere el fragmento donde se narra el desmayo que la madre experimenta al concluir el trabajo de parto:

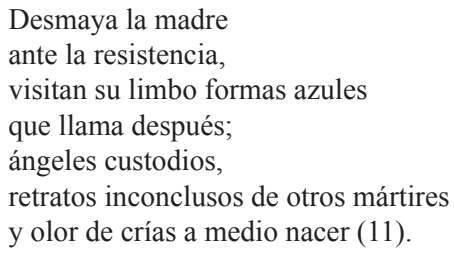

Quizás por eso, ha decidido convocar apoyos en este trayecto por el mundo que recupera en su bitácora de viaje. De allí, también, que no puedan extrañar esas presencias femeninas que, una y otra vez, aparecen en el texto, sean éstas amigas, hermanas, la propia madre, y hasta esas mujeres consagradas, las religiosas pero también las laicas, que resultan hitos fundamentales en el armado del relato. Entre éstas, sin duda, el principal referente es esa Virgen de las Antenas, con la que la hablante se espejea a lo largo del poema, y que, al final del recorrido, ha perdido su condición inmaculada para trasformarse en una mujer más, en una prostituta, en una compañera cómplice y aún en esa madre que, como afirma la hablante, "no cierra los ojos nunca para cuidarme a mí" (51). Una figura que, habiendo operado en nuestro territorio un proceso de mestizaje como consecuencia de la Conquista y de una colonialidad que ya lleva siglos, mira a sus hijas desde lo alto del cerro sabiendo de los dolores y abusos que han padecido en tanto sujetos históricamente violentadas:

La virgen del cerro San Cristóbal se llama virgen de la inmaculada concepción. Al cerro Tupahue le cambiaron el nombre y le pusieron cerro San Cristóbal en honor al santo patrono de los viajeros. O sea de los colonos.

O sea de los violadores.

Los nombres de nuestras madres están cambiados.

Todos nuestros nombres están cambiados.

El cerro no es un violador, el cerro es de las vírgenes violadas.

Siempre anónimas, mudas (80). 
Pero, junto con la Virgen, también aparecen en el poema otras mujeres consagradas, laicas en este caso, que resultan esenciales para orientar el trayecto de la hablante. Pues, desde su magisterio, ellas también irán iluminando su camino y le permitirán autoafirmarse con la seguridad que brinda el saberse parte de una genealogía. Se trata de Marianne Faithfull, Sylvia Platt y, sobre todo, de Gabriela Mistral, poetas cuyas voces, al inicio de cada sección, le señalarán una vía posible para perseverar en el descubrimiento que ella parece perseguir. Una búsqueda a través de la cual el misterio de la Creación se ha transmutado en el proceso de gestación de un lenguaje poético.

\section{BIBLIOGRAFÍA}

Brito, María Eugenia. Vía pública. Santiago: Universitaria, 1984. Filiaciones. Santiago: Cuarto Propio, 1986.

Butler, Judith. “Actos performativos y constitución del género: un ensayo sobre fenomenología y teoría feminista". Debate Feminista. 9/18 (1998): 296-314.

"El Rosario con los misterios comentados e ilustrados", en: http://www.franciscanos.org/ oracion/rosario.html (consulta 2/6/11).

Ferré, Rosario. "La bella durmiente". Papeles de Pandora. México DF: Joaquín Mortiz, 1976.

Hutcheon, Linda. "Ironía, sátira, parodia. Una aproximación pragmática a la ironía". De la ironía a lo grotesco. México D.F.: Universidad Autónoma Metropolitana Iztapalapa, 1992.

Kristeva, Julia. "Stabat Mater". Historias de amor. 1983. México: Siglo XXI Editores, 1987.

Sepúlveda, Magda. "Las poetas y la ciudad de Santiago en la postdictadura chilena (19892006)". En Alicia Salomone, Lorena Amaro y Angela Pérez (editoras). Caminos y desvíos: lecturas críticas sobre género y escritura en América Latina. Santiago: Cuarto Propio, 2010.

Showalter, Elaine. "La crítica feminista en el desierto". En Marina Fe (Ed.). Otramente lectura y escritura feminista. México. FCE, 1999.

Ugalde, Begonia. La Virgen de las Antenas. Santiago: Cuneta, 2011.

Violi, Patrizia, El infinito singular, Madrid: Cátedra, 1991. 